\title{
A Circular Economy Approach for Industrial Scale Biodiesel Production from Palm Oil Mill Effluent using Microwave Heating: Design, Simulation, Techno-economic Analysis and Location Comparison
}

\author{
Harry Waudby and Sharif H. Zein* \\ Department of Chemical Engineering, Faculty of Science and Engineering, \\ University of Hull (UoH), Kingston Upon Hull, HU6 7RX, UK.
}

\begin{abstract}
This paper examines a green approach to produce industrial-scale biodiesel from a palm oil mill effluent (POME) using Microwave Heating. Kinetic data were determined for this reaction and implemented into the Aspen HYSYS simulation software to produce an economic analysis of the process. It was found that the process is economically feasible with the inclusion of significant recycle streams and additional separation equipment. It was found that Malaysia might be the best location to repurpose palm oil mill effluent (POME) because of palm oil production density. Thailand provides modest sea access and the best direct connection with mainland Asia, proving advantageous when distributing biodiesel fuel. Although Malaysia shares this connection to the mainland, terrestrial transport would have to travel a greater distance, increasing costs and emissions. Indonesia, however, offers the largest number of potential plant locations with direct sea access.
\end{abstract}

Keywords: Biodiesel; palm oil mill effluent (POME); Microwave Heating; Techno-economic analysis; Simulation; Circular economy.

*Corresponding Author: E-mail: s.h.zein@hull.ac.uk, Tel: +44 1482466753. 


\section{Abbreviations}

CAPEX: Capital Expenditure

CE: Circular Economy

ILUC: Indirect Land-Use Change

IMS-GT: Indonesia-Malaysia-Singapore Growth Triangle

ISBL: Inside Battery Limits

MRT: Microwave Reactor Technology

OPEX: Operational Expenditure

OSBL: Outside Battery Limits

POME: Palm Oil Mill Effluent 


\section{Introduction}

Biodiesel is a suitable alternative to standard diesel fuels manufactured from petroleum sources. It is primarily formed by transesterification of triglycerides (esters of fatty acids with glycerol) and alcohol, to produce alkyl esters, which biodiesel is comprised of (Knothe, Krahl and Gerpen, 2010). Feedstock costs significantly influence the viability of commercial biodiesel production. In some cases, the total cost comprises upwards of $75 \%$ feedstock purchases (Haas et al., 2006), and it is because of this that attempting to utilise waste biomass is essential. Furthermore, this results in frequent fluctuation as primary biodiesel feedstocks (Vegetable oil, methanol, etc.) are prone to change (Gupta and Demirbas, 2010). Circular economy (CE) initiatives, such as recovery, recycling and reuse, promote carbon reduction, resource security and economic competitiveness (European Commission, 2015). This research deals with a specific waste stream, currently problematic from the environment's perspective, of an industry of importance for several countries in the Global South. Successfully implemented, CE approaches could contribute substantially to the UN Sustainable Development Goals (Schroeder et al., 2019).

The oil palm cultivation areas are situated on and around the equator, with the most significant growth density localising within Malaysia and Indonesia (Fitzherbert et al., 2008). Indonesia is the world's leading palm oil producer and Malaysia the second largest. In 2015, Indonesia and Malaysia accounted for 54\% and 32\% of the world palm oil supply (Mahlia et, 2019). One of the main recommendations by Mukherjee and Sovacool, (2014) who studied palm oil-based biodiesel produced in the countries of, Indonesia, Malaysia and, Thailand, was the development of new biofuel technologies to improve the efficiency of current production methods. Situating a plant using the novel process developed in the prior experimental work, in one of these major palm oil producers, would help improve biodiesel's current production efficiency by converting the POME waste. Therefore, there is economic pressure to construct an industrial POME to biodiesel plant in Southeast Asia and environmental pressure. Governments often subsidise companies or technologies that minimise their environmental impact, so there is the potential that by aiming for environmental improvement, a company may gain some form of economic benefit, potentially through lower taxation. Often it is economically beneficial for a process to use waste feedstocks instead of 'pure' feedstocks and is normally due to the producers desired to offload waste materials that would otherwise incur a cost for their removal and treatment (Towler and Sinnott, 2013). 
Currently, biodiesel production's economic performance is the predominant factor restricting wide-scale production (Silalertruksa, Bonnet and Gheewala, 2012). As such, the main drive for completing this research is to create a process that could, in theory, provide biodiesel at competitive rates to standard petroleum diesel. If this were accomplished, then there would be a more remarkable shift to use biodiesel as a renewable fuel, as suppliers and consumers would not suffer financially for attempting to reduce their impact on the environment. Additionally, biodiesel appears to be a better investment of research effort than some other renewable fuels, namely bioethanol, where it has been seen that biodiesel provides better energy gains and reductions in emissions (Hill et al., 2006). The feedstock for the proposed process, palm oil mill effluent (POME), is not a widely utilised biomass at present. It tends to be discharged directly into nearby water sources with minimal treatment (Ahmad, Ismail and Bhatia, 2003). Furthermore, biodiesel's sustainability is cemented through consideration of its positive energy yield ratio. The output energy to input energy has been 3.53 and 1.44, for palm biodiesel and rapeseed biodiesel. Besides, palm biodiesel's combustion is more environmentally friendly than oil-derived diesel, because CO2 emissions can be significantly reduced by $38 \%$ per litre burned (Yee et al., 2009). Therefore, not only does this study have the potential to provide renewable fuel, but also reduce and repurpose the current waste from the oil palm industry. Besides, the fact that the intended feedstock is to be that of waste biomass, avoiding the concern of consuming biomass that would otherwise be utilised as a food source, negating worries of the food versus fuel debate (Valentine et al., 2011; Chen and Khanna, 2012; Kuchler and Linnér, 2012).

Although POME's repurposing as a biodiesel feedstock, is of environmental value, there are still various concerns highlighted by researchers of biodiesel's negative impact on the environment. Numerous sources detailed to potential damage in the form of direct land-use change (Achten and Verchot, 2011; Findlater and Kandlikar, 2011; Hansen, Olsen and Ujang, 2013; Esteves et al., 2016). Increasing amounts of pasture land and natural growths are converted to biodiesel feedstock crops, leading to carbon dioxide absorption reductions. On top of this, there is a subsequent effect termed 'indirect land-use change (ILUC)', where the displacement of existing crop production areas, forces strain onto other lands to meet demand (Silalertruksa and Gheewala, 2012). A prime example of this ILUC is commonly addressed when considering renewable fuels produced from organic matter and frequently manifests in 
the form of the food vs fuel argument (Valentine et al., 2011; Chen and Khanna, 2012; Kuchler and Linnér, 2012; Mahlia et al. 2020).

There is a modest body of literature focusing on microwave-assisted biodiesel production. Reviewing both batch (Leadbeater and Stencel, 2006; Li et al., 2013; Socha and Sello, 2010; Zhang et al., 2010;) and continuous (Barnard et al., 2007; Choedkiatsakul et al., 2015a; Choedkiatsakul et al., 2015b; Lertsathapornsuk et al., 2008) systems demonstrate that microwave technology is well suited for improving on the traditional methods of biodiesel production. Microwave technology can also counter biodiesel's current economic restraints by lowering energy demands, accelerating reaction times, and increasing yields. Some specific catalysts have been developed to harness microwave reactor technology (MRT), such as a microwave absorbing heterogeneous catalyst, $\mathrm{H}_{2} \mathrm{SO}_{4} / \mathrm{C}$ (Yuan, Yang and $\mathrm{Zhu}, 2009$ ).

We recently introduced the new experimental laboratory work focused on the recovery, extraction and esterification of the POME process to produce biodiesel (Davies et al., 2020; Balan et al., 2021; Semilin et al., 2021). The purpose of this article is to develop and optimise a "green" process for biodiesel production, based on our recent experimental work (Davies et al. 2020; Balan et al., 2021; Semilin et al., 2021). The novel practical work focused on refining the single-step extraction-esterification process to produce biodiesel from POME using the MRT. This paper aims to assess the practicability of implementing such a reaction on a largescale process through simulation and modelling. This study will also conduct an economic analysis of the designed production method, both microwave-assisted and a traditionally heated and evaluate the final design against current biodiesel production methods. Furthermore, to effectively determine whether such a plant is economically viable, finding a suitable biodiesel plant location is studied.

\section{Methods}

This work is based upon our prior experimental work (Davies et al., 2020). A block flow diagram (Figure 1) was produced to show the key unit operations and major process streams to aid in simulation development. A further developed overall process flow diagram (Figure 2) is presented in the form of a typical industry PFD. It has shown the potential for recycling streams to recover heptane, methanol, and sulphuric acid. Each unit operation was considered based on 
its necessity to fulfil a particular process goal, such as separation, purification, or reaction. The details of these unit operations are shown in Appendix A.

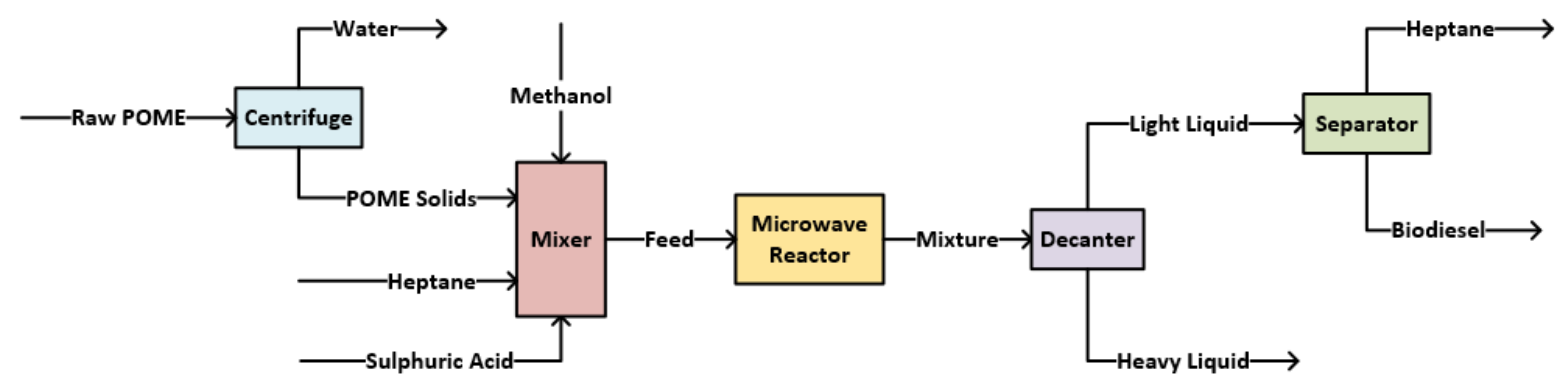

Figure 1 - Basic Process Block Diagram

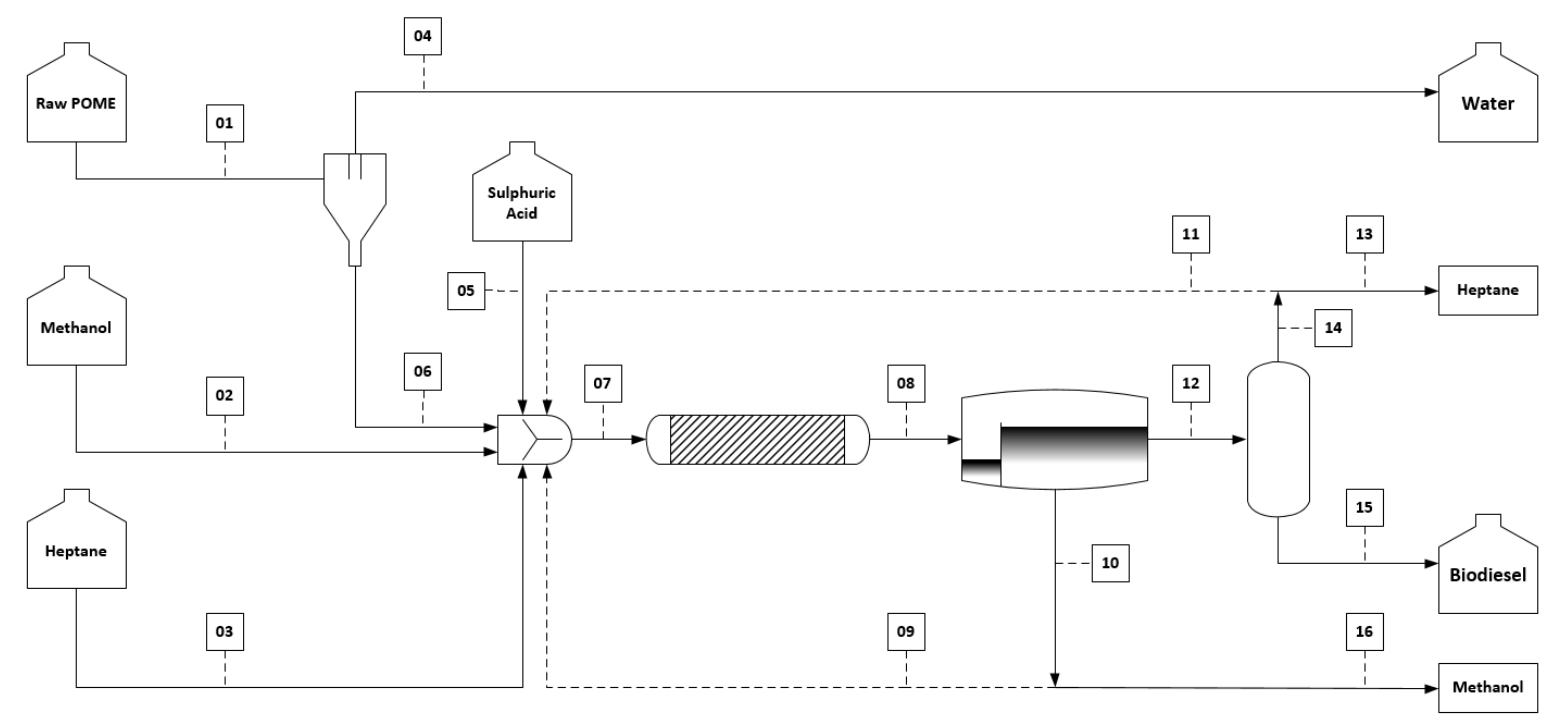

Figure 2 - Simple Process Flow Diagram for POME to Biodiesel Production

\subsection{Source of reaction Data}

The initial data which the reaction kinetics for this paper are based upon were retrieved using the microwave extraction system from Milestone Inc., ETHOS EX. In-depth experimental work is included in our recent work (Davies et al., 2020). In Brief, approximately $15 \mathrm{ml}$ of POME was centrifuged for 30 minutes. The supernatant was set aside, and the pellet was transferred into a temperature-controlled microwave container. The organic solvent and acid catalyst were subsequently added; the container was sealed and placed in the microwave. Microwave heating was carried out at the required temperature. Following the reaction, the system is cooled down to ambient temperature. Six experiments were performed at two separate temperature settings of $150^{\circ} \mathrm{C}$ and $100^{\circ} \mathrm{C}$ for a total of twelve experiments (shown in Table 1). After the set durations, the reaction vessel had to be removed and then left to cool 
down before analysing. Additionally, reaction vessel removal and the subsequent cool-down period produced concern that the stated microwave reaction time did not accurately reflect the actual total reaction duration. As such, two separate kinetic determinations were carried out. This determination was further justified as a large deviation from known literature values was observed during the first kinetic study. The first kinetic determination, termed 'unadjusted', does not include the initial measurements for both temperatures at a time of 1 minute. This exclusion ensures that the reaction rate relies solely on known time steps between recorded data points, which as all samples are cooled for roughly the same time. This extra time where reaction would still occur can be effectively cancelled out. It is further clarified by considering the initial time step, which as the first point is at zero seconds (with no cooling period). The second point is at 1 minute (with roughly 15 minutes of cooling), the time step is not 1 minute but instead around 16 minutes total as the cool-down periods cannot be cancelled out.

Table 1 - Initial microwave-assisted esterification experimental data

\begin{tabular}{cccc}
\hline $\begin{array}{c}\text { Reaction } \\
\text { Number }\end{array}$ & $\begin{array}{c}\text { Temperature } \\
\left({ }^{\circ} \mathrm{C}\right)\end{array}$ & $\begin{array}{c}\text { Time in Microwave } \\
\text { Reactor }(\mathrm{min})\end{array}$ & $\begin{array}{c}\text { Biodiesel (palmitic acid } \\
\text { methyl ester) concentration } \\
\text { at the end }(\mathrm{mg} / \mathrm{ml})\end{array}$ \\
\hline 1 & 1 & 1.307 \\
2 & 2 & 1.600 \\
3 & 150 & 6 & 1.687 \\
4 & & 10 & 1.713 \\
5 & & 12 & 1.760 \\
6 & 15 & 1.893 \\
\hline 7 & 1 & 0.433 \\
8 & & 2 & 0.513 \\
9 & & 6 & 0.967 \\
10 & 100 & 10 & 1.173 \\
11 & & 12 & 1.287 \\
12 & & 15 & 1.373 \\
\hline
\end{tabular}

\subsection{Material Components}

For the simulation setup in Aspen HYSYS, several materials comprised the component list necessary to fulfil an accurate physical reaction representation. The components were given in Table 2. Although POME waste contains various organic acids, only palmitic acid has been 
included within the simulation. This inclusion has been done for some key reasons. Firstly, many research papers studying biodiesel production tend to simulate a single acid or triglyceride feedstock, often oleic acid, to reduce the complexity of simulation setup as the organic acids behave similarly. Secondly, the prior experimental work produced data specifically for palmitic acid conversion and no other acids. Considering the above reasons in conjunction with the knowledge that palm oil contains primarily palmitic acid and subsequently so does POME waste, then the assumption that the acid in POME is $100 \%$ palmitic is regarded as reasonable for these simulation purposes.

Table2 - Simulation component summary

\begin{tabular}{|c|c|c|c|}
\hline Component Name & Process role & Simulation Name & Simulation Type \\
\hline Heptane & $\begin{array}{c}\text { Solvent } \\
\text { (phase separation) }\end{array}$ & n-Heptane & Pure Component \\
\hline Methanol & Feedstock & Methanol & Pure Component \\
\hline Methyl palmitate & Product & M-Palmitate & Pure Component \\
\hline Palmitic acid & Feedstock & 1C16oicAcid & Pure Component \\
\hline $\begin{array}{l}\text { Plant matter } \\
\text { (Cellulose) }\end{array}$ & Feedstock (Inert) & Cellulose* & $\begin{array}{c}\text { User Defined } \\
\text { Hypothetical Solid }\end{array}$ \\
\hline Sulphuric acid & Acid catalyst & $\mathrm{H} 2 \mathrm{SO} 4$ & Pure Component \\
\hline Water & Product & $\mathrm{H} 2 \mathrm{O}$ & Pure Component \\
\hline
\end{tabular}

\subsection{Modelling Solid Plant matter}

Plant matter was assumed to be entire of cellulose material for simplification of simulations. It was set as a hypothetical solid in Aspen HYSYS. As either, it required an additional component package that was not available or had not yet been implanted into the software. Two main properties defined this solid: molecular weight of 162.14 g.mol ${ }^{-1}$, and a density of $1500 \mathrm{~kg} \cdot \mathrm{m}^{-3}$ (Green and Perry, 2008). 
The simulation has been set up to not include the plant matter in the decanter unit operation. This exclusion caused issues with the separation, in that it deviated significantly from experimental evidence. Therefore, a solid separator was placed before the decanter to remove the solids before entering the separation unit. In actuality, the plant matter would be found in the heavy liquid phase. Thus, the solids separator would be placed after the decanter to process the heavy liquid before its possible recycling in the pre-reactor mixer. Plant matter was primarily included in the simulations to provide general calculations of solid waste quantities and determine the 'actual' reactor size, which would be larger due to the flow of plant matter that would take up reactor volume.

\subsubsection{Property Packages}

To model the entire process, including all unit operations, within a single HYSYS simulation required the use of multiple property packages. For most of the process, the NRTL property package was used because of its common use in other researchers studying on simulations of similar biodiesel production processes (Aboelazayem, Gadalla and Saha, 2018a \& b; Lee, Posarac and Ellis, 2011; Santana et al., 2010). Additionally, property packages were chosen with the aid of the Aspen HYSYS property package selection assistant, selecting packages that allowed for polar systems due to the presence of polar compound water (100 polarity) and methanol (76.2 polarity) (Smallwood, 1996) throughout many of the systems unit operations.

However, there is the involvement of phase separation for the gravity settling operation, which required a different fluid package to reflect the experimentally observed separation correctly. The UNIQUAC property package is based on the universal quasi-chemical equation. It represents liquid-liquid equilibria for both binary and multicomponent nonelectrolyte systems (Abrams and Prausnitz, 1975). Therefore, the UNIQUAC package has been used for the phase liquid-liquid phase separation step of this process. It is observed that both palmitic acid and sulphuric acid can be regarded as electrolytes through their dissociation in water (Cleveland and Morris, 2009), which could invalidate the property package. However, their relative concentrations are deficient during the phase separation step. Hence, it has been assumed that their effect on phase equilibrium is negligible.

\subsubsection{Reaction Set}

The reaction set used in the reactor operation was specified as a liquid phase kinetic reaction using the values obtained during the kinetic study, with stoichiometric coefficients reflecting the fundamental esterification reaction. Forward reaction orders were set as those determined 
during the kinetic analysis, with approximately 1.25 for palmitic acid and zero for methanol because of its excess condition. Furthermore, due to the excess methanol, the reaction was considered non-reversible as per literature recommendation, resulting in all reversion order coefficient equalling zero.

\subsubsection{Feed Streams}

All feed streams were assumed to initially be at atmospheric conditions of $20^{\circ} \mathrm{C}$ and $1 \mathrm{~atm}$ as no specific deviations from this were required based on a review of each component's material safety data sheet. Component conditions for safe storage for heptane (Sigma-Aldrich, 2020a), methanol (Sigma-Aldrich, 2020b), and sulphuric acid (Sigma-Aldrich, 2020c) were studied. The POME feed mass composition was taken as that shown below, based upon several literature sources (Ahmad et al., 2006; Igwe and Onyegbado, 2007; Lam and Lee, 2011; Wu et al., 2010):

- Water: $95 \%$

- Plant matter: $4 \%$

- Palmitic acid: $1 \%$

Both heptane and methanol were assumed as $100 \%$ pure to simplify the simulation concerning impurities, considering that many of the available chemical suppliers offer qualities of $\geq 99.9 \%$. Sulphuric acid appears to have a slightly larger percentage of impurities. However, it is utilised on a smaller scale compared to other raw materials, and hence it has also been considered $100 \%$ pure.

\subsection{Economic Analysis}

Economic analysis of the proposed biodiesel production route was conducted in three parts. The first is the utilisation of the cost estimating techniques outlined by Towler and Sinnott (2013). Second, the built-in Aspen HYSYS economic analysis tool will be used to produce an estimate based solely on the simulated design, followed by a final comparison of the produced results.

Before the bulk of the economic analysis was conducted a rough initial estimate was produced to determine whether the fundamental reaction (Equation 1) of the process is intrinsically profitable or not. This analysis was accomplished by simply deducting the total reactant feedstock costs from the sale value of the produced products, using the below assumptions:

- $100 \%$ reaction conversion. 
- Produced biodiesel is $100 \%$ pure methyl palmitate.

- Waste streams do not incur a cost.

- $\quad$ POME is purchased at no cost (Waste material)

$$
\begin{gathered}
\mathrm{CH}_{3} \mathrm{OH}+\mathrm{CH}_{3}\left(\mathrm{CH}_{2}\right) \mathrm{COOH} \rightarrow \mathrm{CH}_{3}\left(\mathrm{CH}_{2}\right) \mathrm{COOCH}_{3}+\mathrm{H}_{2} \mathrm{O} \\
(\text { Methanol })+(\text { Palmitic acid }) \rightarrow(\text { Methyl palmitate })+(\text { Water })
\end{gathered}
$$

\subsection{Location Comparison}

As this project aims for a greener approach to biodiesel production, reducing transportation also reduces the operations emissions. Close to source conversion of POME means less chance for the highly polluting liquid to be discharged into the local river systems. Therefore, this location comparison will consider a singular POME to biodiesel production plant situated close to the source of POME waste. Consequently, the three major palm oil-producing countries were chosen for the comparison. For this comparison, three key factors were used, which were:

- Country's corporation tax - Used to assess the potential impact on annual revenues.

- Location Construction Factor - Used to assess potential savings in capital costs.

- Annual Palm Oil production - Uses to assess the ability to provide required POME capacity.

\section{Results}

\subsection{Reaction Analysis}

The second kinetic determination is termed 'adjusted'. It includes the initial measurements for both temperatures. Still, with an adjustment factor to account for the cool-down period, which is added to the microwave reaction time to produce a total reaction duration that can be seen in Table 3. As it would be difficult knowing exactly how much of the concentration change occurred specifically during the cool-down period. Hence, trial and error estimation was used to determine the adjustment factors until the two temperature settings' reaction orders were approximately equal and close to literature values. A key constraint that was enforced on the estimated values was that the cool-down period for the $100^{\circ} \mathrm{C}$ temperature reactions would be less than that of the $150^{\circ} \mathrm{C}$ as reaction vessels were opened and examined and just below $100^{\circ} \mathrm{C}$. Another reason for this second determination was that in fast reactions, such as the one understudy, most of their essential reaction data is within the beginning period of reaction. Therefore, the necessity to remove the first-time step in the unadjusted data results in data 
points mostly near the 'end' of the reaction where a change in reaction rate has slowed significantly. A breakdown of the kinetic study is produced in the following section, showing the comprised steps for the unadjusted data set; the adjusted data will be stated and discussed for conciseness.

The initial experimental data were used to determine the reaction rate at the midpoints between the set time intervals, with a conversion of mass concentration to molar concentration, and time from minutes to seconds for easier future input into the Aspen HYSYS simulation software shown in Table 3. A graphical curve fitting method was used to determine the reaction rate at any point, for both temperature conditions (Figure 3). This method was for two reasons: firstly, the obtained experimental data did not have consistent time intervals, and as such, a numerical approach was not suitable. Secondly, it allowed for easier identification of any erroneous results and a better understanding of the rate of reaction and reaction time relationship.

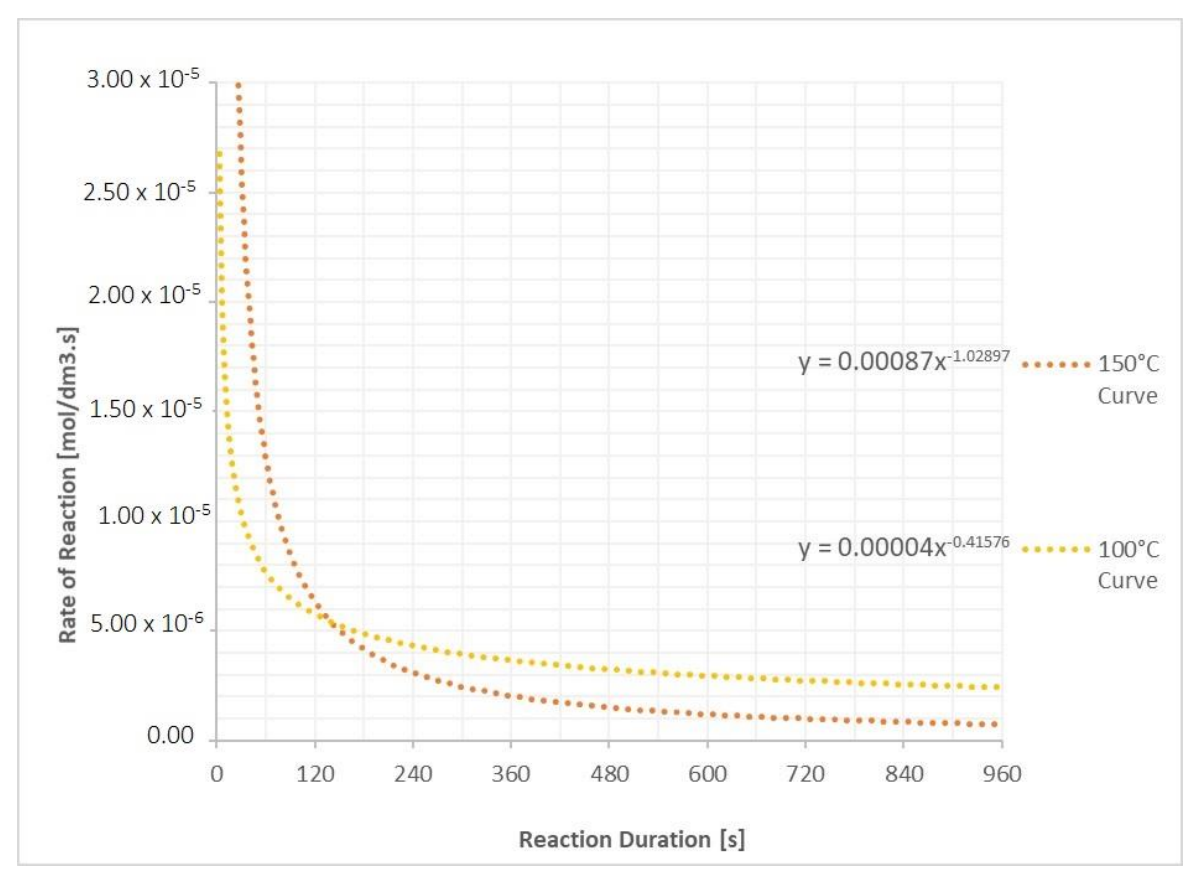

Figure 3 - Unadjusted Temperature effect on reaction rate comparison 


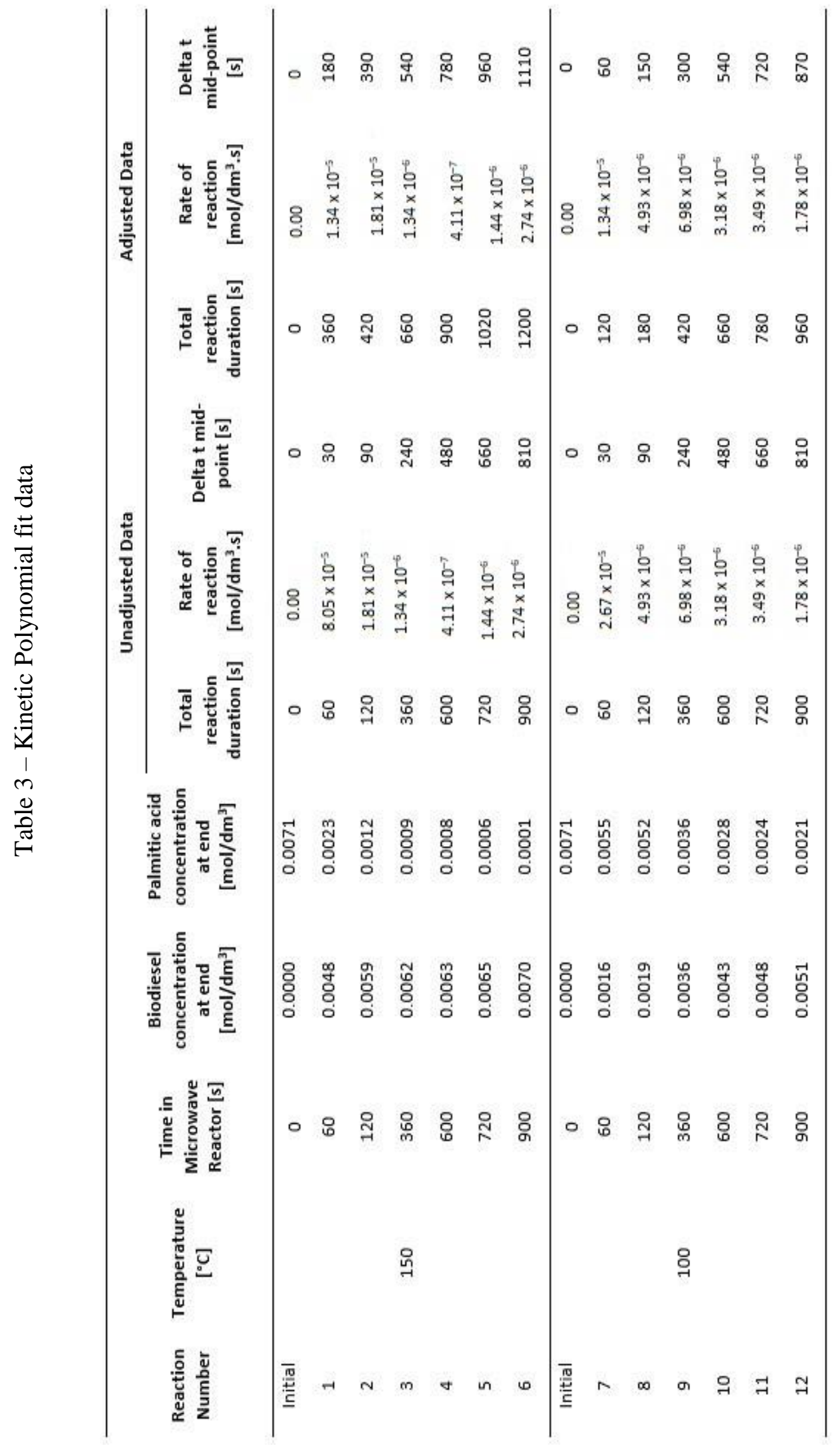


Figure 3 shows the temperature setting of $150^{\circ} \mathrm{C}$ provides a faster reaction rate at the start of the process, but this changes after around 2 minutes. The $100^{\circ} \mathrm{C}$ setting begins to give a slightly faster rate. This initial variance in rate makes sense as a higher temperature should reflect a higher reaction rate, via a higher rate constant, based on the Arrhenius expression. The crossover point of the two curves will likely be where the $150^{\circ} \mathrm{C}$ reactions are already nearing completion and will have slowed significantly. It is reinforced by comparing the conversions at $82.9 \%$ and $26.6 \%$, for $150^{\circ} \mathrm{C}$ and $100^{\circ} \mathrm{C}$ respectively. Plotting the data using equation (2) allows for the simultaneous determination of both the rate constants $\mathrm{k}_{1}$ and $\mathrm{k}_{2}$, and reaction order $\alpha$. A plot has been produced for each temperature condition and is shown in Figure 4.

$$
\ln \left(\frac{d C_{A}}{d t}\right)=\alpha \ln \left(C_{A}\right)+\ln (k)
$$

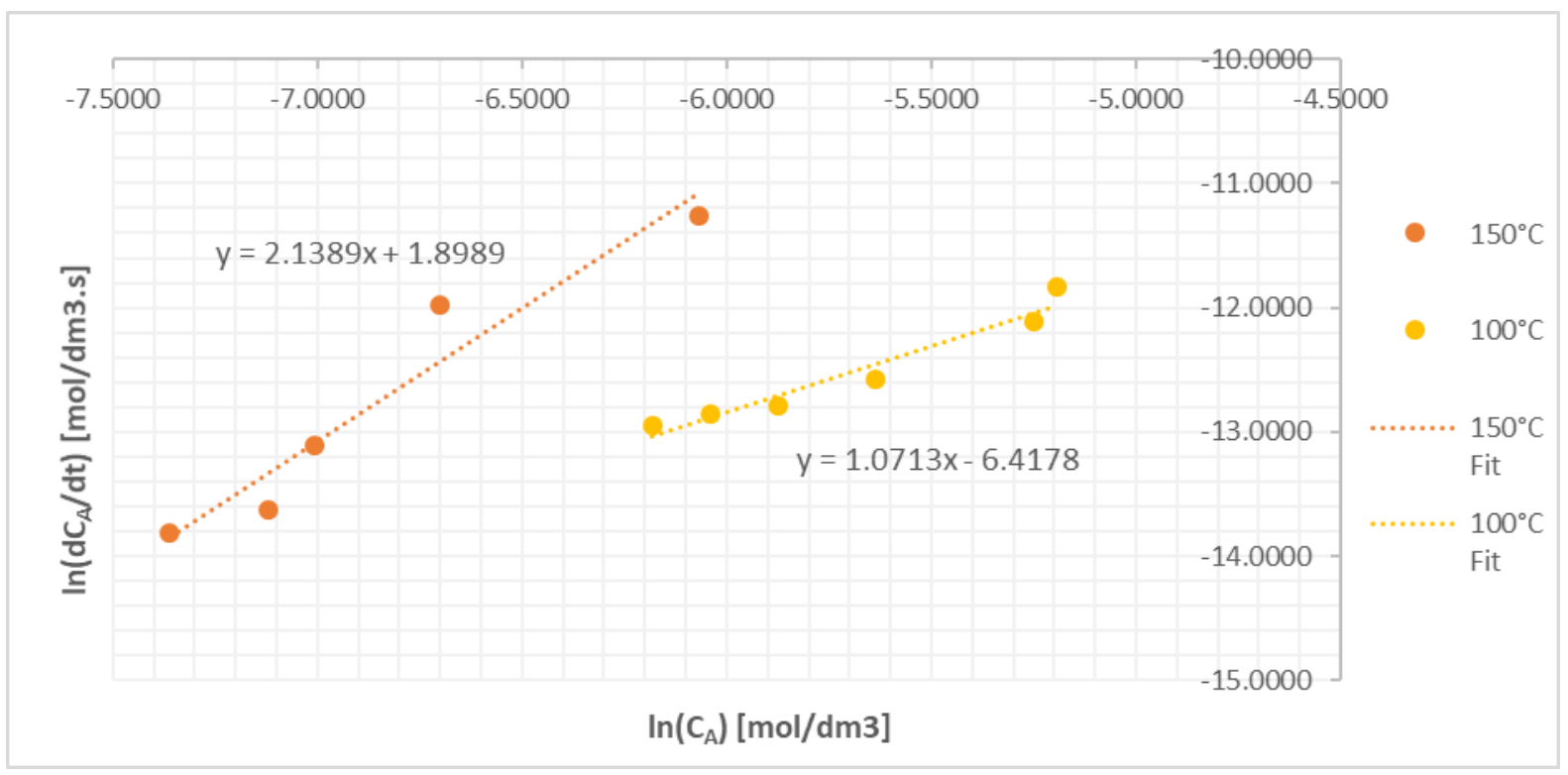

Figure 4 - Unadjusted Rate constant determination

Figure 4 shows that the orders of reaction from the unadjusted kinetic study appear to vary significantly with a temperature change. Due to the limits of the experimental data and how the kinetic values were obtained, it is difficult to determine whether this significant variance is caused by erroneous data or accurate representation. However, reaction orders are said to only vary slightly with temperature and in some cases are entirely independent of it (Coker, 2001). Therefore, this reaction order discrepancy reinforced the decision to perform an adjusted study. Although there was concern at this stage of the research, the process was followed through to produce final values for reaction kinetics to allow future comparison of results. Combining the 
Arrhenius equation (3) for each temperature condition produces the expression (4), which can be used to determine the activation energy, $\mathrm{E}_{\mathrm{a}}$, from the obtained rate constants.

$$
\begin{gathered}
k=A \cdot \exp \left(\frac{-E_{a}}{R T}\right) \\
E_{a}=\frac{R T_{1} T_{2}}{\left(T_{1}-T_{2}\right)} \ln \left(\frac{k_{1}}{k_{2}}\right)
\end{gathered}
$$

Once the activation energy has been calculated, all known values can be substituted into the Arrhenius equation's rearranged form (5) to determine the pre-exponential factor, A.

$$
\frac{k}{\exp \left(\frac{-E_{a}}{R T}\right)}=A
$$

From the unadjusted data set, the following reaction kinetic data were produced:

- Activation energy, $\mathrm{E}_{\mathrm{a}}=218.2 \mathrm{~kJ} \cdot \mathrm{mol}^{-1}$

- Pre-exponential factor $\mathrm{A}=5.88 \times 10^{27} \mathrm{~s}^{-1}$

While this supposed activation energy is not unreasonable, as most reactions fall within the range of 50-250 kJ.mol ${ }^{-1}$ (Richardson and Peacock, 1994), it alongside the pre-exponential factor is significantly distinct from other literature sources for similar biodiesel production studies. Preliminary simulations using this data suggested reactor sizes that appeared to be unusually small for the given industrial plant throughput, which was a key reason that prompted the re-evaluation of the initial kinetic data study and brought forth the concept of two parallel studies.

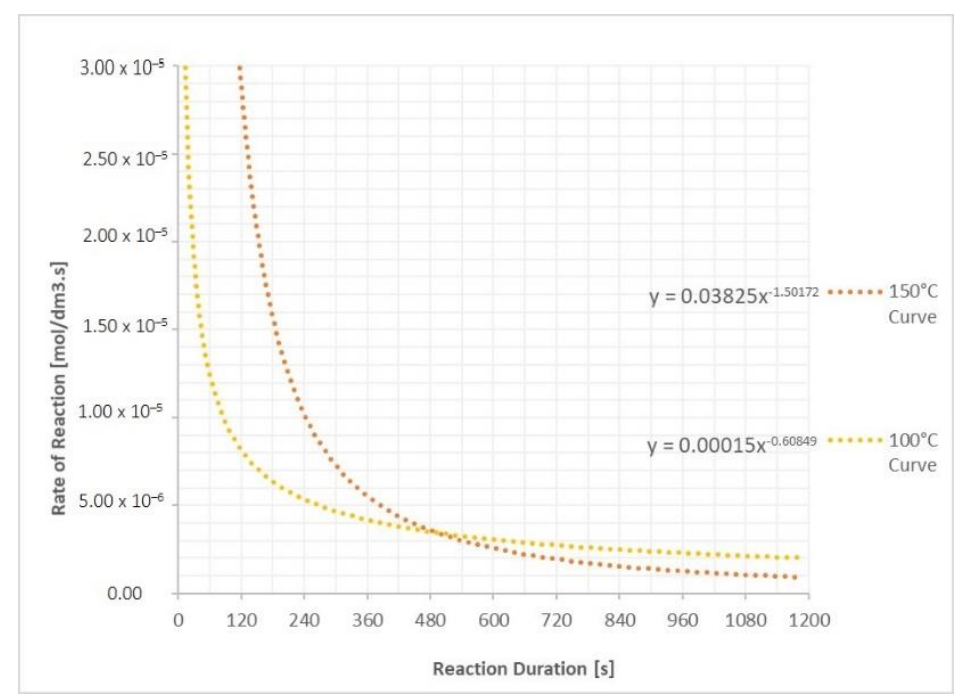

Figure 5 - Adjusted Temperature effect on reaction rate comparison 
As expected from the modification to the reaction time steps, the reactions occur over a long period now that the data include the vessel cool-down period (Figure 5). Although the curves are different from the unadjusted set, the overall relationship remains the same; the higher temperature $150^{\circ} \mathrm{C}$ reactions proceed faster earlier on in the process with the eventual swap where the $100^{\circ} \mathrm{C}$ reactions begin to react faster as the high-temperature reaction nears completion.

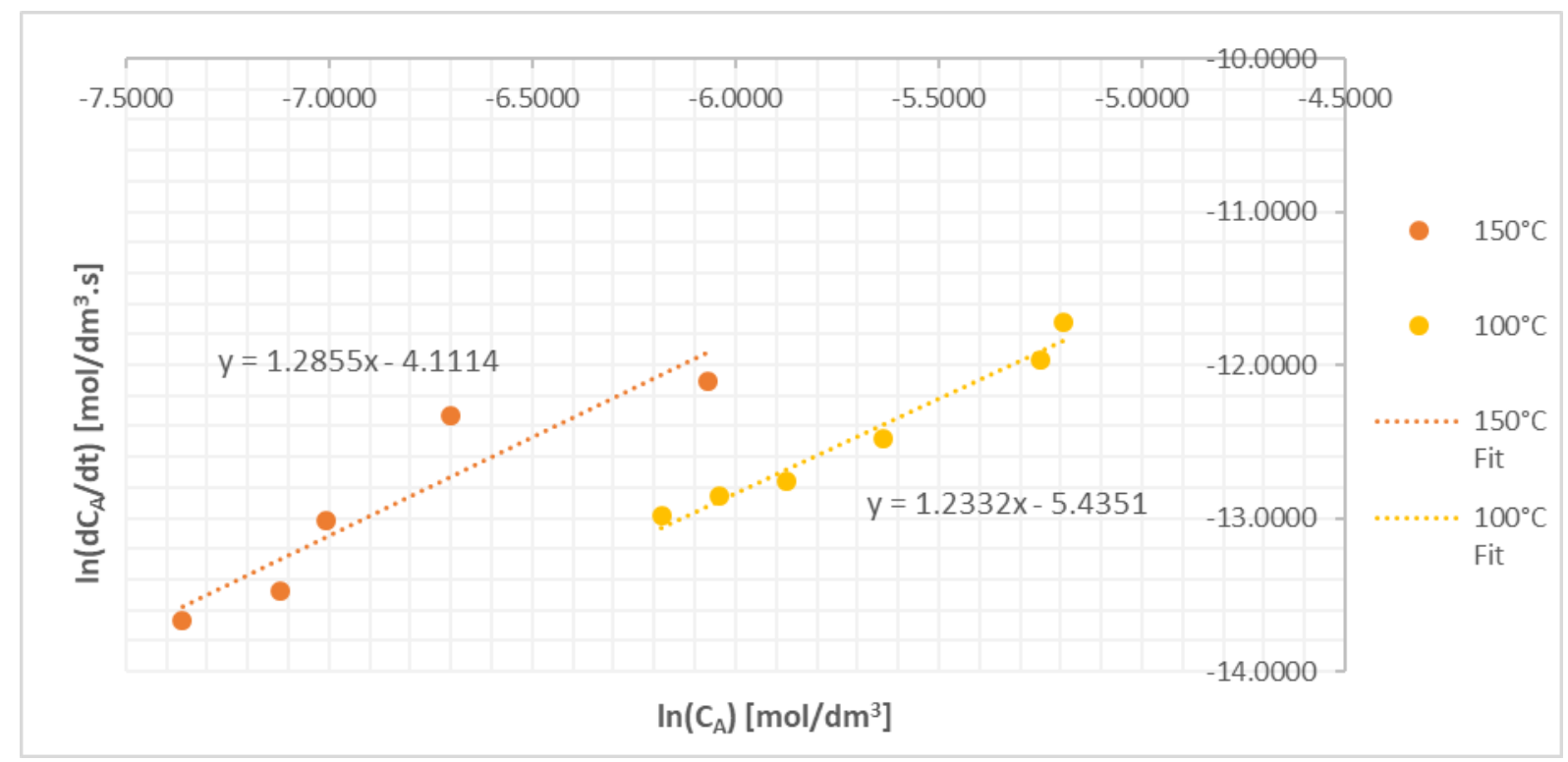

Figure 6-Adjusted rate constant determination

As was discussed earlier in the report, this graph (Figure 6) was used to determine the cooldown adjustment factor's suitability by considering the relative reaction orders. It was found that the most reasonable cool-down periods were 5 minutes and 1 minute, for $150^{\circ} \mathrm{C}$ and $100^{\circ} \mathrm{C}$ respectively. From the adjusted data set, the following reaction kinetic data were produced:

- Activation energy, $\mathrm{E}_{\mathrm{a}}=34.7 \mathrm{~kJ} \cdot \mathrm{mol}^{-1}$

- Pre-exponential factor $\mathrm{A}=318.43 \mathrm{~s}^{-1}$

Unlike the previous results from the unadjusted kinetic data, these values much more closely follow those of other literature sources. Additionally, this data produced simulated reactor scales that were more realistic than that of the unadjusted data set. 


\subsection{Simulation Flowsheet}

After completing the setup, the simulation process began by focusing on the reactor section and then building outwards. This process allowed each unit operation to be added sequentially to the overall flow sheet, where their performance could be reviewed before proceeding to the next piece of equipment. Construction of the full process in a single step would have resulted in a lack of confidence in the individual operations. It would have made it challenging to identify if and where an error had occurred.

As the mixer unit operation is a simple process that is easily implemented into Aspen HYSYS, it has not been given a detailed breakdown of its simulation setup. Other subsidiary operations such as heaters, coolers, and pumps were set to the default values recommended by HYSYS. The solids removal after the reactor unit, as previously discussed, is primarily included to allow for accurate separation of the liquid phases in the decanter and therefore was also not given an individual breakdown. It was decided that simulation names for streams and equipment (Figure 7) were chosen based on their descriptions instead of using a numbered naming convention commonly used for industrial purposes. This decision was made because the overall flowsheet was not that complicated and that descriptive names aided a viewer in understanding the process. The details of these unit operations are shown in Appendix B.

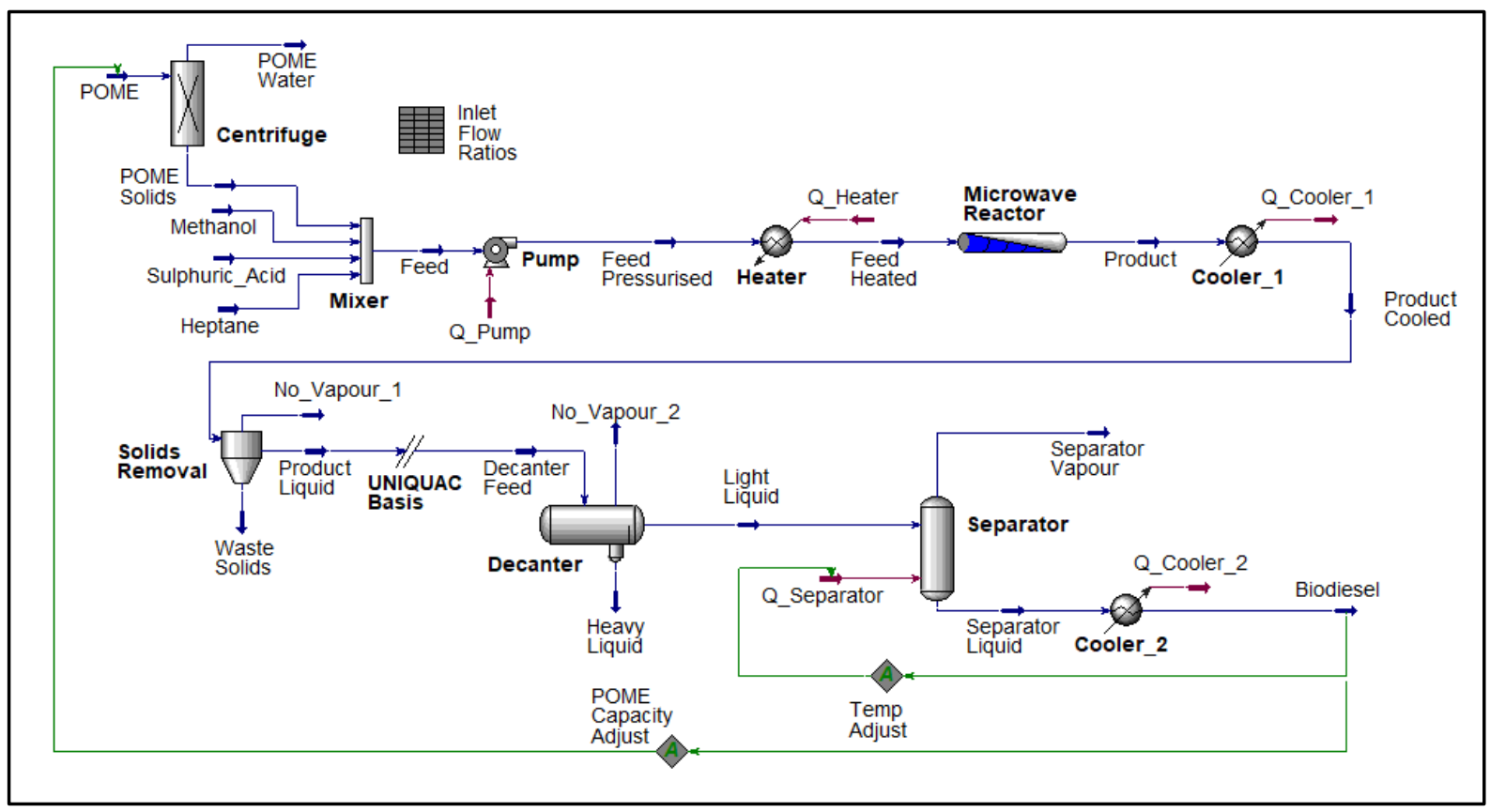

Figure 7 - Aspen HYSYS overall simulation flowsheet 


\subsubsection{Modified Design}

During the economic assessment of the process, it was discovered that based on the simulation, an economical setup that the initial primitive design would not be profitable. It was mainly due to the design's simple nature where unused materials were left as outlet streams, which resulted in a high cost to maintain the solvent's flow rates and excess solvent streams. Therefore, a more advanced design was required to assess better the process's economic feasibility (Figure 8). Due to the above observation, the focus was initially made to reduce heptane's requirement through a recycling stream. As most of the heptane initially fed into the system ended up being present in the vapour stream, leaving the final separator, this stream was targeted for heptane recycle. Before recycling this stream, it was fed into an additional decanter to separate the heptane water. This separation improved the heptane percentage from approximately $70 \%$ to $90 \%$ whilst maintaining most of the total mass flow. However, due to this simple/coarse separation method, any methanol present separated from the water. Thus, as the primary goal was to improve the economics of the process, it was decided that the optimum way to accomplish this was to provide no subsequent separation of the methanol and water, as it would be too costly relative to the quantity of methanol recovered. Overall the addition of this recycles operation drastically reduced the feedstock requirements of heptane, which can be seen in Table 4.

Table 4 - Modified Design Feedstock Comparison

\begin{tabular}{ccc}
\hline Feedstock & Adjusted Mass Flow $[\mathrm{kg} / \mathrm{h}]$ & Modified Mass Flow [kg/h] \\
\hline Heptane & 324 & 49 \\
Methanol & 1331 & 205 \\
Sulphuric Acid & 109 & 8 \\
\hline
\end{tabular}




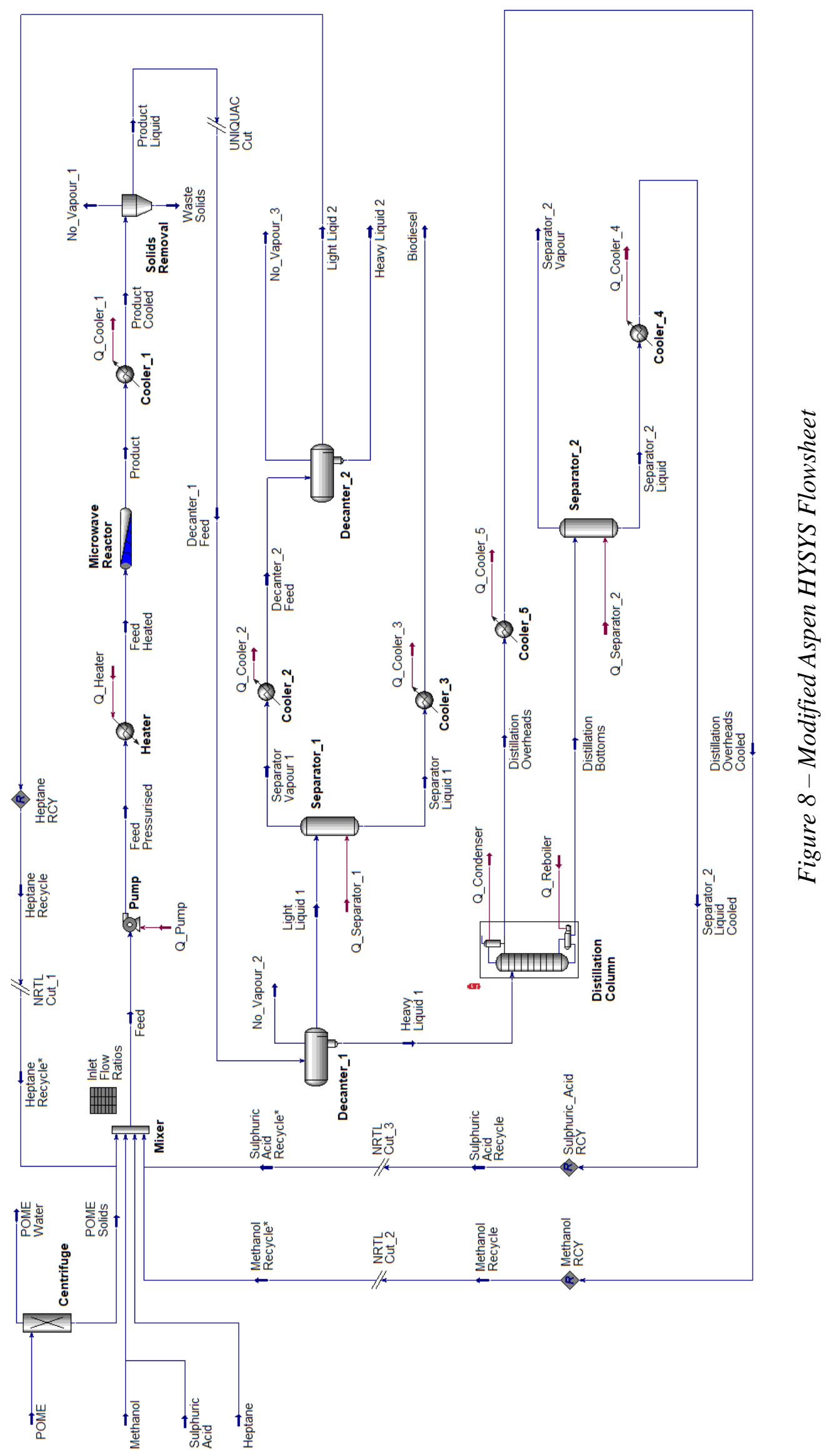


Based on this heptane recycling principle and further improving the process economy, another keystream, the heavy liquid stream leaving the initial settling, was identified for recycling. This stream contained the catalyst, water, and the majority of excess methanol. The elimination of water was not as trivial as in heptane, because of the desire to recover methanol and sulphuric acid. As a result, a multi-stage separation was determined to be necessary. For initial trials, another flash separator was included followed by another. Still, a fair split of water and methanol could not be achieved, resulting in a large quantity of water being recycled, reducing the reaction section's efficiency. Therefore, a distillation column was used to provide an improved separation, designed using two specifications: the methanol percentage in the overheads and the bottoms' water percentage. Final values for these, which produced a converged simulation, were $98 \%$ methanol and $82 \%$ water in their respective streams. The sulphuric acid was then separated from the water bottoms stream via an additional flash separator, producing a high concentration catalyst recycle stream. Reductions in the feedstock requirements for the complete modified design, including the three recycling functions, can be seen in Table 4. Specific material stream and composition data for this simulation process can be seen in Appendix C.

\subsection{Preliminary reaction economics}

Summary of inherent reaction annual economics is given in Table 5. From this annual profit, it can be seen that under the set assumptions that the reaction process itself is economically viable. This statement's reliability is reinforced as the assumptions are close to reality where, the reaction is close to $100 \%$ conversion, produces an easily separable product. That POME is frequently discharged to river systems. 
Table 5 - Summary of inherent reaction annual economics

\begin{tabular}{cccccc}
\hline & Methanol & $\begin{array}{c}\text { Palmitic Acid } \\
\text { (Within POME) }\end{array}$ & $\begin{array}{c}\text { POME } \\
\text { (1\% Palmitic Acid) }\end{array}$ & $\begin{array}{c}\text { Methyl } \\
\text { Palmitate }\end{array}$ & Water \\
\hline $\begin{array}{c}\text { Molecular mass } \\
\text { [kg/kmol] }\end{array}$ & 32.04 & 256.43 & - & 270.46 & 18.02 \\
$\begin{array}{c}\text { Stoichiometry } \\
\begin{array}{c}\text { Mass flow } \\
\text { [tonnes/year] }\end{array}\end{array}$ & 1,185 & 9,481 & 948,125 & 10,000 & 666 \\
$\begin{array}{c}\text { Price } \\
\text { [USD/tonne] }\end{array}$ & 360 & - & 0 & 1,102 & 0 \\
$\begin{array}{c}\text { Cost [USD }] \\
\text { (WS }\end{array}$ & 426,473 & - & 0 & $11,023,110$ & 0 \\
\hline
\end{tabular}

\subsection{Economic Analysis using cost estimating techniques}

Total capital investment for the theoretical plant has been calculated using the assumptions given in Appendix D and rules of thumb, resulting in an initial estimate of $\$ 4.15$ million with a breakdown of intermediate calculations shown in Table 6. Conversion for a 2000 to 2018 basis was made using the annual CEPCI values of 394 and 607, respectively.

Table 6 - Summary of economic analysis using cost estimating techniques

\begin{tabular}{ccc}
\hline Plant Cost & Assumption & $\mathbf{\$ \times 1 0 ^ { \mathbf { 6 } }}$ \\
\hline ISBL (2000 basis) & Scaled from similar plant & 0.93 \\
ISBL (2018 basis) & Multiplied by CEPCI factor & 1.43 \\
OSBL & $40 \%$ of ISBL & 0.57 \\
ISBL + OSBL & - & 2.01 \\
Engineering & $30 \%$ of (ISBL + OSBL) & 0.60 \\
Contingency & $30 \%$ of (ISBL + OSBL) & 1.00 \\
Fixed Capital & ISBL + OSBL + Engineering + Contingency & 3.61 \\
Working Capital & $15 \%$ of Fixed Capital & 0.54 \\
Total Capital Investment & Working + Fixed & 4.15 \\
\hline
\end{tabular}




\subsection{Aspen HYSYS economic assessment}

Aspen HYSYS was used to obtain the economic data for four different process scenarios, one for each of the obtained kinetic data sets using the initial flowsheet, and additional assessment of the modified design using the adjusted kinetic data. Each economic evaluation used the same economic scenario to allow for direct comparison between the produced cost data. The economic scenario details, stream costs, utility costs, and equipment costs are given in Appendix E and associated Table E1 - E2.

\subsection{Cost Comparison}

Although the three cost estimates not utilising recycled streams are not profitable, they can still compare the reactor performance based upon the used kinetic data. Out of the three cost estimates based on the initial design, the reactor using the literature kinetic data produced the most economical process. It is mainly due to the capability of its reaction to being performed at a much lower temperature. Therefore, it requires reduced operating costs, outweighing the additional expense incurred by requiring an increased reactor volume, necessary to match the other simulation setups' reaction conversions.

Table 7 - Economic Analysis Comparison Summary

\begin{tabular}{|c|c|c|c|c|c|}
\hline & Recycle & Adjusted & Unadjusted & Literature & Unit \\
\hline Total Project Capital Cost & $7.96 \times 10^{6}$ & $5.46 \times 10^{6}$ & $5.27 \times 10^{6}$ & $5.19 \times 10^{6}$ & USD \\
\hline Total Operating Cost & $3.13 \times 10^{6}$ & $1.15 \times 10^{7}$ & $1.17 \times 10^{7}$ & $1.13 \times 10^{7}$ & USD/Year \\
\hline Total Raw Materials Cost & $1.40 \times 10^{6}$ & $9.30 \times 10^{6}$ & $9.43 \times 10^{6}$ & $9.31 \times 10^{6}$ & USD/Year \\
\hline Total Utilities Cost & 341542 & 234656 & 238047 & 58786.1 & USD/Year \\
\hline Total Product Sales & $9.00 \times 10^{6}$ & $9.00 \times 10^{6}$ & $9.00 \times 10^{6}$ & $9.00 \times 10^{6}$ & USD/Year \\
\hline P.O. Period & 15.2772 & 0 & 0 & 0 & Year \\
\hline Reactor Volume & 1 & 1 & 0.0025 & 2 & m3 \\
\hline Reactor Installed Cost & 214300 & 214300 & 85,100 & 174,600 & USD \\
\hline Reactor Temperature & 150 & 150 & 150 & 34 & ${ }^{\circ} \mathrm{C}$ \\
\hline Heater Cost & 136800 & 136700 & 136900 & 75500 & USD \\
\hline
\end{tabular}


Suppose the original kinetic data can be confirmed with additional experimental retrials. In that case, it appears that the microwave-assisted reaction can function with significantly reduced reactor sizes, and therefore minimise the construction and installation costs of the unit operation. However, suppose the actual reaction kinetics are more in line with those of the adjusted data set (which includes a cool-down factor). In that case, the increased reaction temperature does not reduce plant costs. The vessel size is relatively comparable to that of the traditional heating method, but with increased heating costs. It should be noted that the microwave-assisted process's actual operating costs might be significantly lower than what has been stated in these simulation results. It may be to Aspen HYSYS which does not provide the selection of alternative utility heating, such as that of microwave radiation. So instead traditional steam heating was chosen. However, as most operating costs are comprised of raw materials costs, it is felt that this will not have significantly affected the profitability of the nonrecycled cases.

The initial class 5 estimate predicted a value of $\$ 4.15 \times 10^{6} \pm 50 \%$ (Table 6) for the total project capital cost. In contrast, the initial simulation flowsheet produces values within this range. The modified recycle simulation significantly exceed this range (Table 7). This large discrepancy is most likely explained due to the significant cost incurred by the initial POME liquid-solids separator of around $\$ 1 \times 10^{6}$ (Table E2) which is necessary for removing the large quantities of water from the waste feedstock. It is not present in the more traditional design used as the cost basis for the class 5 estimate.

Building on this observation, it would appear that the most critical area for optimisation of this process would be the pre-reaction feedstock preparation. In these cost estimates, a single disk centrifuge was used, and therefore there may be the potential to reduce costs through multiple units working in parallel. Additionally, the previously mentioned technique could be used, where a hydrocyclone precedes the centrifuge to provide an initial coarse separation with minimal costs. The inclusion of recycle streams in the modified simulation flowsheet resulted in significant reductions in raw material costs and consequently converted the process into a profitable one. However, the inclusion of these recycle streams required additional process equipment and therefore incurred a substantial increase in the project's capital cost. From the profitability of this modified design, it could be suggested that a POME to biodiesel process has good potential to be economically viable on an industrial scale. 


\subsection{Location Comparison}

As feedstock, operation, and transport costs vary significantly between different locations; it is sensible to determine a particular location suitable for the theoretical plant. Furthermore, to effectively determine whether such a plant is economically viable, it is necessary to identify whether a convenient location exists.

The site's location is often positioned at one of two places, either the final products destination or the major feedstock source. The intent is to minimise transportation costs. POME, its composition of close to $95 \%$ water content, transporting this away from the source will be a costly and illogical endeavour. The ratio of the POMEs volume of product produced is inferior. Additionally, it could be suggested that POME is first processed for water removal and then transport to the biodiesel production site. However, this leads to the case of two geographically separate facilities of the same operation, which will both be required to be independent and incur the costs of two processing plants. If this is considered in conjunction with the rule of plant scaling where the money is saved the larger a chemical plant, then two smaller plants will likely result in higher capital and operating costs than one large combined plant.

There is no clear leader in terms of economic merit for the selected countries, as corporation tax appears to vary inversely to the examined locations' construction factor (Table 8). Therefore, the site location will primarily depend on the balance of operational expenditure (OPEX) and capital expenditure (CAPEX); if a designed plant using this technology has a high CAPEX but low OPEX, Indonesia will likely provide the best location for economic performance. Conversely, if the opposite were true, Thailand would probably be the most suitable location to deliver financial success.

Considering that the high ratio of POME waste to palm oil produced, all of these Southeast Asian countries will generate a considerable amount of POME waste. The plant's feedstock demand is easily covered within realistic plant capacities (Table 8). Although all the countries are equally viable in meeting this feedstock requirement, Indonesia would offer the most promising location for future development and expansion due to the enormous quantity of POME produced. Moreover, Indonesia would offer the most significant potential for environmental damage reduction as it has the greatest amount of POME waste that requires disposal. 
Figure 9 was produced to compare and understand the relatively available landmass and sea trade route capabilities for each of the respective countries. The city-state of Singapore and Brunei's small nation have been included on the map due to their proximity and geometric situation within the other countries of interest. Indonesia has the largest amount of available landmass, reflecting its place as the largest palm oil producer. However, Malaysia appears to produce the greatest amount of biodiesel per amount of available land, with roughly seven times the production rate of Thailand (Table 8) with approximately equal available land (Figure 9). Therefore, Malaysia might be the best location to repurpose the greatest amount of waste per POME to the biodiesel plant because of palm oil production density.

\section{Table 8 - Biodiesel Plant Location Comparison Data}

\begin{tabular}{cccc}
\hline & Thailand & Malaysia & Indonesia \\
\hline $\begin{array}{c}\text { Corporation Tax } \\
\text { (TRADING ECONOMICS, 2019) }\end{array}$ & $20 \%$ & $24 \%$ & $25 \%$ \\
$\begin{array}{c}\text { Location Construction Factor } \\
\text { (Cost Data On Line, Inc., 2008) }\end{array}$ & 1.22 & 1.14 & 1.09 \\
$\begin{array}{c}\text { Annual Palm Oil Production 2018 } \\
\text { [megatonnes] (IndexMundi, 2019) }\end{array}$ & 2.9 & & \\
\hline
\end{tabular}

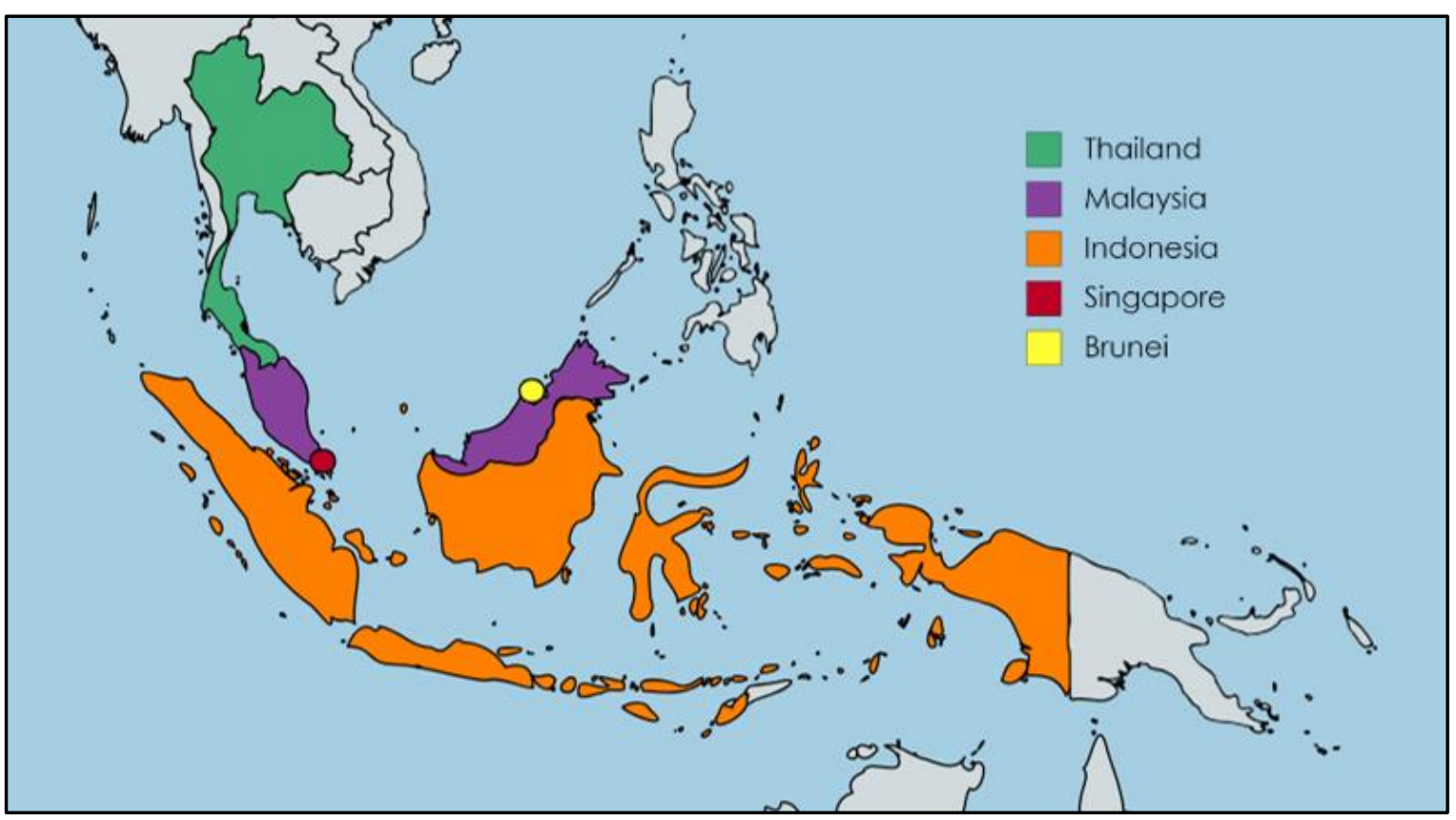

Figure 9-Map of potential POME to biodiesel plant location (created using mapchart.net) 
In terms of transportation availability, Thailand provides modest sea access and the best direct connection with mainland Asia, proving to be advantageous when distributing the produced biodiesel fuel. Although Malaysia shares this connection to the mainland, terrestrial transport would have to travel a greater distance, increasing costs and emissions. Indonesia, however, offers the largest number of potential plant locations with direct sea access. Malaysia has an interesting dynamic in that it has two independent nations within its geography, which could provide unique factors for consideration for the plant location. One such consideration is the proposed Indonesia-Malaysia-Singapore Growth Triangle (IMS-GT), the concept of regional cooperation through the free movement of goods, services, and labour to provide mutual economic benefit (Smith, 1997). Similarly, Brunei's nation may offer an interesting consideration due to its large amount of wealth stemming from its petroleum and natural gas exportation and researchers' suggestion that it needs to undergo economic diversification to remain prosperous (Tasie, 2009). Brunei might consider expanding its exports through collaboration and funding of nearby biofuels projects, such as a POME to biodiesel production based in Malaysia.

\section{Discussion}

Currently, the world faces many environmental challenges by humans' technological and industrial development, and none is more important than climate change. Through the exploitation of fossil fuels and lack of sustainable ideals, the environment is being continually damaged in this way. Therefore, as the chemical industry is a major contributor to these factors, it needs to minimise its environmental impact. This microwave-assisted POME to biodiesel method provides a potential way of simultaneously reducing the discharge of polluting waste and production of biofuel with minimised atmospheric emissions.

While the body of literature surrounding microwave-assisted processes is limited, it tends to focus heavily on biofuel production methods, cementing the idea that microwave reactors are well suited for biodiesel production. Numerous researchers explore the environmentally damaging effects of POME waste disposal. Considering the enormous scale of the oil palm industry, numerous researchers provide a significant incentive to implement a process that can successfully repurpose POME waste. 
For this POME to biodiesel method, kinetic reaction data, activation energy, and preexponential factor were successfully determined based on experimental lab-scale trials and implemented into the Aspen HYSYS simulation software. A simulation was produced from this data that confirmed biodiesel's reaction capabilities with high conversion and fast reaction rate.

An economic analysis was carried out to access the commercial viability of the project. Initial simplistic process designs produced unprofitable production methods, but this was overcome by including recycling streams and additional separation units, to achieve an economically feasible process. This feasibility is further justified because only basic optimisation and design were conducted on the process. A virtual team of experienced process engineers could likely make substantial improvements in the profitability of this process. Additionally, it is reaffirmed here that the project's objective was to assess the process of economic feasibility, not to design the most efficient and cost-effective process possible.

From the location comparison, it appears that while each of the selected countries is close in their suitability for a POME to the biodiesel plant, Indonesia is likely the best choice. Indonesia provides a large amount of land with good transportation access, the most significant POME waste production. Based on the estimated plant capital cost (Table 7) it provides the lowest construction factor. It will, therefore, result in the best potential for cost reduction.

While the final modified process simulation flowsheet appears to be economically profitable, several observations can be made that highlight some significant differences between this design and current production methods. A major difference is a necessity for a large water removal processing unit, to prepare the feedstock for the reaction step, incurring high processing costs to utilise this waste feedstock. Depending on whether this step can be optimised, the advantage of using POME appears to be significantly hindered through the challenge of separating the solid matter and free fatty acids. Although many current biodiesel production methods will require some form of feedstock preparation, especially in the case of those using waste materials, like cooking oil, they are not needed on the same scale of that required for POME processing.

Another major difference is that this method uses harsh operating conditions (high temperatures and pressures) to require increased capital costs through better quality materials. 
It will also need a great deal of consideration for safety and control systems. On the other hand, current methods tend to use only slightly above atmospheric reaction conditions, while there are supercritical conditions. These are not widely implemented in industrial applications. The development of a POME for biodiesel plant would require an increased engineering effort who would likely need to lean on the experience of other harsh conditions fields.

Many current processes focus on the transesterification reaction. There may be a lack of highly specialised catalysts and an awareness of their applications for this microwave-assisted esterification process. However, this project's initial experimental work used the common acid catalyst, sulphuric acid, for its experimental trials, demonstrating that a standard commercial catalyst could be used for this process in much the same way as in current biodiesel production.

Overall, an industrial POME to biodiesel process appears to provide a promising alternative to current production methods. It also enhances the biofuel industry's 'green' capabilities by providing a process that simultaneously removes a highly polluting waste, produces a biofuel, produces potentially reusable water, and reduces reaction vessel dimensions. Besides, a single biodiesel POME plant located close to the POME waste source reduces emissions from operations. The high-pollution liquid is less likely to be discharged into the local river.

To further access this production method's appropriateness for commercial biodiesel, the produced biofuel product should be physically examined for its combustive properties. The fatty acid composition directly influences biodiesel's more important physicochemical properties (Ongle et al., 2020). Biodiesel has lower stability than diesel (Dunn and Knothe, 2003). Biodiesel is chemically an ester molecule. It has superior lubricity, lower toxicity, higher flash point, biodegradability and negligible sulphur content (Moser, 2009). However, the presence of alcohol and acid will reduce the flash point and increase the total number of acids. Biodiesel's low stability is also caused by double bonds in fatty acids, resulting in gums' formation. These factors render the methyl ester relatively unstable in storage and cause damage to the engine parts (Sarin et al., 2007). Besides, lower volumetric energy content and inferior low-temperature operability are other disadvantages (Moser, 2009). These tests could be carried out similar to other research papers that compare biodiesel's performance to traditional petroleum diesel by running the fuel through a commercial vehicle engine (Monyem 
and Gerpen, 2001). The engine performance could be analysed through such a method and the exhaust emissions and the effects of oil palm plant matter build-up and fouling.

\section{Conclusion}

In keeping with CE principles, a full-scale a microwave-assisted POME to biodiesel production process has been designed and simulated. The kinetic data were determined in the temperature range of $100-150^{\circ} \mathrm{C}$, with values of $34.7 \mathrm{~kJ} \mathrm{~mol}^{-1}$ and $318 \mathrm{~s}^{-1}$ for activation energy and pre-exponential factor, respectively. The process is economically feasible by including significant recycled streams and separation processes producing biodiesel close to commercial EU standards. Therefore, it is estimated at USD 7,960,000 and USD 3,130,000 for the factory's capital and operating costs, respectively. It appears that a country close to the creation of POME waste would be best for plant locations.

\section{CRediT author statement}

Harry Waudby: Investigation, Data curation, Writing- Original draft preparation.

Sharif Zein: Conceptualisation, Supervision, Writing- Reviewing and Editing.

\section{Conflict of Interest}

On behalf of all authors, the corresponding author states that there is no conflict of interest.

\section{Funding}

This research did not receive any specific grant from funding agencies in the public, commercial, or not-for-profit sectors.

\section{References}

Aboelazayem, O., Gadalla, M. and Saha, B. (2018a). Biodiesel production from waste cooking oil via supercritical methanol: Optimisation and reactor simulation. Renewable Energy, 124, pp.144-154.

Aboelazayem, O., Gadalla, M. and Saha, B. (2018b). Design and simulation of an integrated process for biodiesel production from waste cooking oil using supercritical methanolysis. Energy, 161, pp.299-307. 
Abrams, D. S and Prausnitz, J. M. (1975). Statistical thermodynamics of liquid mixtures: A new expression for the excess Gibbs energy of partly or completely miscible systems. AlChE J., 21, pp116-127.

Achten, W. and Verchot, L. (2011). Implications of Biodiesel-Induced Land-Use Changes for CO2 Emissions: Case Studies in Tropical America, Africa, and Southeast Asia. Ecology and Society, 16(4).

Ahmad, A., Chong, M., Bhatia, S. and Ismail, S. (2006). Drinking water reclamation from palm oil mill effluent (POME) using membrane technology. Desalination, 191(1-3), pp.35-44.

Ahmad, A., Ismail, S. and Bhatia, S. (2003). Water recycling from palm oil mill effluent (POME) using membrane technology. Desalination, 157(1-3), pp.87-95.

Balan, W. S., Janaun, J., Chung, C.H., Semilin, V., Zhu, Z., Haywood, S. K., Touhami, D., Chong, K. P., Yaser, A. Z., Lee, P. C., Zein, S. H. (2021). Esterification of residual palm oil using solid acid catalyst derived from rice husk, Journal of Hazardous Materials, Volume 404, Part B.

Barnard, T., Leadbeater, N., Boucher, M., Stencel, L. and Wilhite, B. (2007). Continuous-Flow Preparation of Biodiesel Using Microwave Heating. Energy \& Fuels, 21(3), pp.17771781 .

Chen, X. and Khanna, M. (2012). Food vs. Fuel: The Effect of Biofuel Policies. American Journal of Agricultural Economics, 95(2), pp.289-295.

Choedkiatsakul, I., Ngaosuwan, K., Assabumrungrat, S., Mantegna, S. and Cravotto, G. (2015a). Biodiesel production in a novel continuous flow microwave reactor. Renewable Energy, 83, pp.25-29.

Choedkiatsakul, I., Ngaosuwan, K., Assabumrungrat, S., Tabasso, S. and Cravotto, G. (2015b). Integrated flow reactor that combines high-shear mixing and microwave irradiation for biodiesel production. Biomass and Bioenergy, 77, pp.186-191.

Cleveland, C. and Morris, C. (2009). Dictionary of Energy. Amsterdam: Elsevier.

Coker, A. (2001). Modeling of Chemical Kinetics and Reactor Design. Houston, Texas: Gulf Professional Publishing.

Cost data on line, Inc. (2008). Richardson Products International Construction Factors Manual. Availale online: http://www.icoste.org/Book_Reviews/CFM-Info.pdf [Accessed 10/03/2019]

Davies, E., Deutz, P. and Zein, SH (2020). Single-step extraction-esterification process to produce biodiesel from palm oil mill effluent (POME) using microwave heating: a circular economy approach to making use of a difficult waste product. Biomass Conv. Bioref. (2020). https://doi.org/10.1007/s13399-020-00856-1

Ong, H.C.; Mofijur, M.; Silitonga, A.S.; Gumilang, D.; Kusumo, F.; Mahlia, T.M.I. Physicochemical Properties of Biodiesel Synthesised from Grape Seed, Philippine Tung, Kesambi, and Palm Oils. Energies 2020, 13, 1319. https://doi.org/10.3390/en13061319

Esteves, V., Esteves, E., Bungenstab, D., Loebmann, D., de Castro Victoria, D., Vicente, L., de Queiroz Fernandes Araújo, O. and do Rosário Vaz Morgado, C. (2016). Land use change (LUC) analysis and life cycle assessment (LCA) of Brazilian soybean biodiesel. Clean Technologies and Environmental Policy, 18(6), pp.1655-1673 
European Commission (2015) Closing the loop - an EU action plan for the circular economy. European Commission, Brussels

Findlater, K. and Kandlikar, M. (2011). Land use and second-generation biofuel feedstocks: The unconsidered impacts of Jatropha biodiesel in Rajasthan, India. Energy Policy, 39(6), pp.3404-3413.

Fitzherbert, E., Struebig, M., Morel, A., Danielsen, F., Bruhl, C., Donald, P. and Phalan, B. (2008). How will oil palm expansion affect biodiversity?. Trends in Ecology \& Evolution, 23(10), pp.538-545.

Green, D. and Perry, R. (2008). PERRY'S CHEMICAL ENGINEERING HANDBOOK. 8th ed. London: McGraw-Hill.

Gupta, R. and Demirbas, A. (2010). Gasoline, diesel and ethanol biofuels from grasses and plants. Cambridge: Cambridge University Press.

Haas, M., McAloon, A., Yee, W. and Foglia, T. (2006). A process model to estimate biodiesel production costs. Bioresource Technology, 97(4), pp.671-678.

Hansen, S., Olsen, S. and Ujang, Z. (2013). Carbon balance impacts of land use changes related to the life cycle of Malaysian palm oil-derived biodiesel. The International Journal of Life Cycle Assessment, 19(3), pp.558-566.

Hill, J., Nelson, E., Tilman, D., Polasky, S. and Tiffany, D. (2006). Environmental, economic, and energetic costs and benefits of biodiesel and ethanol biofuels. Proceedings of the National Academy of Sciences, 103(30), pp.11206-11210.

Igwe, J. and Onyegbado, C. (2007). A Review of Palm Oil Mill Effluent (Pome) Water Treatment. Global Journal of Environmental Research, 1(2), pp.54-62.

IndexMundi (2019). Palm Oil Production by Country in 1000 MT. Available online: https://www.indexmundi.com/agriculture/?commodity=palm-oil [Accessed 10/03/2019]

Knothe, G., Krahl, J. and Gerpen, J. (2010). The Biodiesel Handbook, $2^{\text {nd }}$ edition. Urbana: AOCS Press.

Kuchler, M. and Linnér, B. (2012). Challenging the food vs. fuel dilemma: Genealogical analysis of the biofuel discourse pursued by international organisations. Food Policy, 37(5), pp.581-588.

Lam, M. and Lee, K. (2011). Renewable and sustainable bioenergies production from palm oil mill effluent (POME): Win-win strategies toward better environmental protection. Biotechnology Advances, 29(1), pp.124-141.

Leadbeater, N. and Stencel, L. (2006). Fast, Easy Preparation of Biodiesel Using Microwave Heating. Energy \& Fuels, 20(5), pp.2281-2283.

Lee, S., Posarac, D. and Ellis, N. (2011). Process simulation and economic analysis of biodiesel production processes using fresh and waste vegetable oil and supercritical methanol. Chemical Engineering Research and Design, 89(12), pp.2626-2642.

Lertsathapornsuk, V., Pairintra, R., Aryusuk, K. and Krisnangkura, K. (2008). Microwave assisted in continuous biodiesel production from waste frying palm oil and its performance in a $100 \mathrm{~kW}$ diesel generator. Fuel Processing Technology, 89(12), pp.1330-1336. 
Li, Y., Ye, B., Shen, J., Tian, Z., Wang, L., Zhu, L., Ma, T., Yang, D. and Qiu, F. (2013). Optimisation of biodiesel production process from soybean oil using the sodium potassium tartrate doped zirconia catalyst under Microwave Chemical Reactor. Bioresource Technology, 137, pp.220-225.

Mahlia, T.M.I., Ismail, N., Hossain, N. et al. (2019) Palm oil and its wastes as bioenergy sources: a comprehensive review. Environ Sci Pollut Res 26, 14849-14866. https://doi.org/10.1007/s11356-019-04563-x

Mahlia T.M.I.,, Syazmi, Z.A.H.S., Mofijur, M., Abas, A.E. Pg., Bilad, M.R., Ong, H. C., Silitonga, A.S. (2020). Patent landscape review on biodiesel production: Technology updates, Renewable and Sustainable Energy Reviews, 118, 109526. https://doi.org/10.1016/j.rser.2019.109526.

Monyem, A. and H. Van Gerpen, J. (2001). The effect of biodiesel oxidation on engine performance and emissions. Biomass and Bioenergy, 20(4), pp.317-325.

Moser, B. R. (2009) Biodiesel production, properties, and feedstocks. In Vitro Cellular \& Developmental Biology - Plant, 45(3), 229-266.

Mukherjee, I. and Sovacool, B. (2014). Palm oil-based biofuels and sustainability in southeast Asia: A review of Indonesia, Malaysia, and Thailand. Renewable and Sustainable Energy Reviews, 37, pp.1-12.

Ong, H.C.; Mofijur, M.; Silitonga, A.S.; Gumilang, D.; Kusumo, F.; Mahlia, T.M.I. (2020). Physicochemical Properties of Biodiesel Synthesised from Grape Seed, Philippine Tung, Kesambi, and Palm Oils. Energies 2020, 13, 1319. https://doi.org/10.3390/en13061319

Richardson, J. and Peacock, D. (1994). Coulson and Richardson's Chemical Engineering Volume 3 - Chemical and Biochemical Reactors and Process Control. 3rd ed. Oxford: Butterworth-Heinemann.

Santana, G., Martins, P., de Lima da Silva, N., Batistella, C., Maciel Filho, R. and Wolf Maciel, M. (2010). Simulation and cost estimate for biodiesel production using castor oil. Chemical Engineering Research and Design, 88(5-6), pp.626-632.

Sarin, R., Sharma, M., Sinharay, S., Malhotra R.K. (2007) Jatropha-Palm biodiesel blends: An optimum mix for Asia, Fuel, Volume 86, Issues 10-11, 2007, 1365-1371, https://doi.org/10.1016/j.fuel.2006.11.040.

Schroeder P, Anggraeni K, Weber U (2019) The relevance of circular economy practices to the sustainable development goals. J Ind Ecol 23(1):77-95

Semilin,V., Janaun, J., Chung, C.H., Touhami, D., Haywood, S. K., Chong, K. P., Yaser, A. Z., Zein, S. H. (2021). Recovery of oil from palm oil mill effluent using polypropylene micro/nanofiber, Journal of Hazardous Materials, Volume 404, Part B.

Sigma-Aldrich (2020a). Heptane Safety Data Sheet. Available online:

https://www.sigmaaldrich.com/MSDS/MSDS/DisplayMSDSPage.do?country=GB\&lang uage $=$ en \&productNumber $=246654 \&$ brand $=$ SIAL\&PageToGoToURL $=$ https $\% 3 \mathrm{~A} \% 2 \mathrm{~F} \%$ 2Fwww.sigmaaldrich.com\%2Fcatalog\%2Fsearch\%3Fterm\%3Dheptane $\% 2$ interface $\% 3$ DAll\%26N\%3D0\%26mode\%3Dmatch\%2520partialmax\%26lang\%3Den\%26region\%3D GB\%26focus\%3Dproduct [Accessed 27/11/2020] 
Sigma-Aldrich (2020b). Methanol Safety Data Sheet. Available online:

https://www.sigmaaldrich.com/MSDS/MSDS/DisplayMSDSPage.do?country=GB\&lang uage $=$ en $\&$ productNumber $=34860 \&$ brand $=$ SIGALD\&PageToGoToURL $=$ https $\% 3 \mathrm{~A} \% 2 \mathrm{~F}$ \%2Fwww.sigmaaldrich.com\%2Fcatalog\%2Fsearch\%3Fterm\%3Dmethanol\%26interface \%3DAll\%26N\%3D0\%26mode\%3Dmatch\%2520partialmax\%26lang\%3Den\%26region \%3DGB\%26focus\%3Dproduct [Accessed 27/11/2020]

Sigma-Aldrich (2020c). Sulphuric acid Safety Data Sheet. Available online: https://www.sigmaaldrich.com/MSDS/MSDS/DisplayMSDSPage.do?country=GB\&lang uage=en\&productNumber $=339741 \&$ brand $=$ ALDRICH\&PageToGoToURL $=$ https $\% 3 \mathrm{~A} \%$ 2F\%2Fwww.sigmaaldrich.com\%2Fcatalog\%2Fsearch\%3Fterm\%3DSulfuric $\% 2$ Bacid $\% 2$ 6interface $\% 3$ DProduct $\% 2520$ Name $\% 26 \mathrm{~N} \% 3 \mathrm{D} 0 \% 2 \mathrm{~B} \% 26$ mode $\% 3 \mathrm{Dmode} \% 2520$ matchp artialmax\%26lang\%3Den\%26region\%3DGB\%26focus\%3DproductN\%3D0\%25202200 03048\%2520219853286\%2520219853121 [Accessed 27/11/2020]

Silalertruksa, T. and Gheewala, S. (2012). Food, Fuel, and Climate Change - Is Palm-Based Biodiesel a Sustainable Option for Thailand?. Journal of Industrial Ecology, 16(4), pp.541551.

Silalertruksa, T., Bonnet, S. and Gheewala, S. (2012). Life cycle costing and externalities of palm oil biodiesel in Thailand. Journal of Cleaner Production, 28, pp.225-232.

Smallwood, I. (1996). Handbook of organic solvent properties. London: Hodder Headline Group.

Smith, S. (1997). The Indonesia-Malaysia-Singapore growth triangle: A political and economic equation. Australian Journal of International Affairs, 51(3), pp.369-382.

Socha, A. and Sello, J. (2010). Efficient conversion of triacylglycerols and fatty acids to biodiesel in a microwave reactor using metal triflate catalysts. Organic \& Biomolecular Chemistry, 8(20), p.4753.

Tasie, G. (2009). Globalisation and economic diversification in the Sultanate of Brunei. African Journal of Business Management, 3(10), pp.511-520.

Towler, G. and Sinnott, R. (2013). Chemical Engineering Design - Principles, Practice and Economics of Plant and Process Design. 2nd ed. Oxford: Butterworth-Heineman.

Trading Economics (2019). List of Countries by Corporate Tax Rate - World. Available online: https://tradingeconomics.com/country-list/corporate-tax-rate [Accessed 10/03/2019]

U. S. Department of Energy (2019) Clean Cities Alternative Fuel Price Report. Available Online:

https://afdc.energy.gov/files/u/publication/alternative_fuel_price_report_jan_2019.pdf [Accessed 16/03/19]

Valentine, J., Clifton-Brown, J., Hastings, A., Robson, P., Allison, G. and Smith, P. (2011). Food vs. fuel: the use of land for lignocellulosic 'next generation' energy crops that minimise competition with primary food production. GCB Bioenergy, 4(1), pp.1-19.

Wu, T., Mohammad, A., Jahim, J. and Anuar, N. (2010). Pollution control technologies for the treatment of palm oil mill effluent (POME) through end-of-pipe processes. Journal of Environmental Management, 91(7), pp.1467-1490. 
Yee, K., Tan, K., Abdullah, A. and Lee, K. (2009). Life cycle assessment of palm biodiesel: Revealing facts and benefits for sustainability. Applied Energy, 86, S189-S196

Yuan, H., Yang, B. and Zhu, G. (2009). Synthesis of Biodiesel Using Microwave Absorption Catalysts. Energy \& Fuels, 23(1), pp.548-552.

Zhang, S., Zu, Y., Fu, Y., Luo, M., Zhang, D. and Efferth, T. (2010). Rapid microwave-assisted transesterification of yellow horn oil to biodiesel using a heteropolyacid solid catalyst. Bioresource Technology, 101(3), pp.931-936. 